\title{
Exploring barriers to and opportunities for the co-management of air quality and carbon in South West England: a review of progress
}

\author{
S. T. Baldwin ${ }^{1}$, M. Everard ${ }^{2}$, E. T. Hayes ${ }^{1}$, J. W. S. Longhurst ${ }^{1}$ \\ \& J. R. Merefield ${ }^{3}$ \\ ${ }^{1}$ Faculty of Environment and Technology, \\ University of the West of England, UK \\ ${ }^{2}$ Environment Agency, Kings Meadow House, UK \\ ${ }^{3}$ Department of Life Long Learning, University of Exeter, UK
}

\begin{abstract}
Due to the common sources of emissions of both air quality pollutants and greenhouse gases, management measures directed at one category of emissions are likely to positively impact the other. Through the local air quality management (LAQM) process, local authorities are required to monitor and measure specified air pollutants, the sources of which are also common to the primary sources of carbon emissions at a local level. This research tracks the progression of local authority management of carbon emissions and examines the barriers and opportunities for the integration of carbon emissions into the LAQM process. Results are triangulated from three core research methods deployed in South West England: a time series of local authority questionnaire surveys; secondary data analysis of active Air Quality Action Plans; and case study interviews of six local authorities in the region. The research concludes that the absence of statutory targets for carbon emission reductions remains a substantial barrier for local authority carbon management initiatives. However, in order to utilise scarce resources in the most efficient manner, local authorities should draw upon the existing skill set of their Air Quality Officers.
\end{abstract}

Keywords: air quality, carbon management, co-benefit, synergy, local government. 


\section{Introduction}

In 2008, the UK passed legislation which introduced the world's first long-term legally binding framework to tackling the dangers of climate change. The Climate Change Act 2008 commits the UK to greenhouse gas emission reductions through action in the UK and abroad of at least $80 \%$ by 2050 , and reductions in $\mathrm{CO}_{2}$ emissions of at least $26 \%$ by 2020, against a 1990 baseline [1]. In order to meet these ambitious targets, the UK must take substantive measures to reduce carbon emissions both nationally and locally. To date, the UK has pursued its goals on carbon mitigation mainly at an international level through programmes such as the United Nations Framework Convention on Climate Change [2], the Kyoto Protocol [3], the European Union Emissions Trading Scheme [4] and nationally through the Climate Change Programme [5]. By contrast the UK has been slow to recognise the important role that locally-driven carbon mitigation can play in contributing to its national and international obligations. While the Climate Change Programme advocated early interventions by public sector organisations, both in reducing the carbon intensity of their own operations and by raising awareness in their local communities [5], it did not go so far as to place a legal duty on local government to take action.

\subsection{Local authority climate change initiatives}

Many local authorities in the UK now recognise the role they can play and have been engaging with voluntary initiatives for tacking climate change and mitigation of carbon emissions. Notable amongst these voluntary initiatives are two schemes. Firstly, the Nottingham Declaration on Climate Change [6] which has been signed by 236 local authorities (as of April 2009) and which commits signatories to three broad aims: acknowledging that climate change is occurring; welcoming and engaging with the government targets; and committing to working at a local level on climate change management. Secondly, the Local Authority Carbon Management Programme [7], through which the Carbon Trust works with 216 participating local authorities to improve energy efficiency and reduce their carbon emissions. In April 2008, the new National Performance Reporting Framework [8] introduced responsibilities for local authorities to achieve year-on-year reductions in carbon emissions from their own operations (National Indicator 185) and reductions in per capita emissions in their administrative area (National Indicator 186). Although the new framework does not explicitly require local authorities to set binding targets for reductions in carbon emissions, it does represent the first consistent local authority-wide approach to monitoring $\mathrm{CO}_{2}$ emissions. The new carbon monitoring responsibilities will require local authorities to build carbon management policies into the full spectrum of their duties and responsibilities. However, the limited resources available to carry out their new duties means local authorities would be wise to utilise existing skills within their authority, particularly in the comparable skill set developed through the LAQM regime. 
There is also growing acknowledgment that air pollution and climate change goals are complementary and should not be pursued in isolation [9]. However, to date, management of the two areas has been largely separate both in Europe and further afield. Current research suggests that considerable ancillary benefits could arise from a more holistic and integrated approach to the management of air pollution and mitigation strategies for carbon emissions [10]. The rationale for these benefits can be divided into four main arguments: the economic benefits of integrated policies $[11,12]$; the role of air pollutants as greenhouse gases; the effect of future climatic conditions on air quality [13]; and synergies and trade-offs arising from management techniques [13].

\subsection{The Local Air Quality Management process}

The Environment Act 1995 required the publication of the first National Air Quality Strategy, the core of which was the setting of a series of health-based standards for eight pollutants [15]. This introduced a statutory requirement for local authorities to periodically review and assess air quality in their area for specified pollutants and to assess current and projected future levels of air quality [16]. These reviews are assessed against a number of national Air Quality Objectives (AQOs) established for seven of the eight priority pollutants. Where an area exceeds, or is likely to exceed, by a stated date, local authorities are required to designate an Air Quality Management Area (AQMA) and develop an Air Quality Action Plan (AQAP) outlining measures they will take to work towards remediating the problem [15]. The application of this process requires many of the same methods, skills and collaborative networks that would be required for an effective carbon management framework at the local level, including: the production of a robust emissions inventory; embedding carbon in the local and regional Air Quality Strategies; collaborative networks between key stakeholders influencing atmospheric emissions; and joint carbon/air quality action plans. Moreover, the Air Quality Strategy for England, Scotland, Wales and Northern Ireland (2007) recognises the importance of considering the impact of air quality measures on carbon emissions by stating that, '...in the development of Air Quality Action Plans and where appropriate, LTPs, local authorities should bear in mind the synergies and trade-offs between air quality and climate change, and the added benefits to the local, regional and global environment of having an integrated approach to tackling both climate change and air quality goals' [17]. This research investigates the opportunities and barriers for local authorities to co-manage carbon emissions at a local level through existing air quality management processes.

\section{Methodology}

Results presented here are taken from three components of a longitudinal study investigating the progress, barriers and opportunities for an integrated approach to the management of air quality and carbon emissions through the Local Air 
Quality Management process in the South West Region of England. Three methods of data collection are presented: two questionnaire surveys (administered in 2008 and 2009); 12 case study interviews in six local authorities; and secondary data analysis of the ten active AQAPs in the region.

The 2008 questionnaire survey was designed to investigate the extent to which traditional air pollutants and carbon emissions are being co-managed at a local governance level in the South West Region of England. The 2009 questionnaire survey was designed to explore the key themes derived from the previous survey and to establish the progression of emerging carbon management strategies within the region. The target group of the questionnaire surveys consisted of all local government bodies in the South West Region of England. Both surveys focused on two key categories of officer in local government: Air Quality Officers; and officers with primary responsibility for carbon management or, where they exist, Climate Change Officers.

The secondary data collection component reviewed the established AQAPs produced by local authorities in response to the declaration of AQMAs. A coding form (survey protocol) was developed to establish the extent to which the action plans considered their impact on climate change. A matrix was constructed to examine specific measures outlined in the AQAPs in more detail. This allowed the identified measures to be categorised as 'synergy', 'trade-off' and 'lose-lose' outcomes regarding the co-management of air quality and climate change.

The case study interviews served to enhance, expand and create depth to research findings. The interviews provided three main purposes: to triangulate data obtained from the questionnaire and secondary data analysis stages of the project; to investigate some of the issues highlighted by the questionnaire surveys; and to gain a clearer understanding of how local authorities are beginning to deal with the climate change issue within the structure and organisation of local government.

\section{Research findings}

Selected results are presented from: two questionnaire surveys (comprising a total of 22 Air Quality Officers and 12 officers with primary responsibility for climate change from South West England); six case study authorities (comprising 12 interviews distributed evenly between Air Quality Officers and officers with carbon management responsibilities); and secondary data analysis of the nine active AQAPs implemented in the region. Results are presented for the following thematic areas: progress in local government carbon management strategies and integrated management of air pollution and carbon emissions; opportunities for integrated management of air pollution and carbon emissions; barriers to integrated management; and challenges for integrated management.

\subsection{Progress in local government carbon management strategies and integrated management of air pollution and carbon emissions}

The LAQM process has become well established within local governments in the UK since its inception over a decade ago, driven in part by a strong legislative 
framework (the Environment Act 1995). The South West Region of England is no exception to this trend, with $100 \%$ of the local authorities in the 2009 questionnaire survey employing a minimum of one officer with responsibility for management of air quality within their administrative area. Conversely, local government has not benefited from a comparable legislative intervention for locally-driven carbon management. Despite this lack of a formalised requirement, local government organisations in the UK have shown increasing recognition in recent years of the role they can play in managing and influencing carbon emissions within their jurisdictions. In the 2009 questionnaire survey, $89 \%$ (8) of respondents reported employing an officer with primary responsibility for carbon management. The production of a Climate Change Strategy is an important first step in highlighting a local authority's commitment to action and organising the measures by which they will achieve reductions and adapt to the future effects of a changing climate. $67 \%$ (6) of respondents had produced a strategy for tackling climate change in their area. This represents a modest increase when compared to the 2008 questionnaire survey response in which $56 \%$ (5) of the same survey group reported having developed a strategy.

\subsection{Opportunities for integrated management of air pollution and carbon emissions}

A number of elements required to implement the LAQM process effectively could directly lend themselves to carbon management at a local level. The multiplicity of air pollution sources (many of which are beyond direct local authority control) often necessitates local authorities to establish strong networks with the organisations, functions and bodies responsible for, or with an influence over, locally-derived emissions. These stakeholders are also likely to be the main sources of locally-generated carbon emissions (i.e. transport, domestic and business). The 2009 questionnaire survey data showed that $65 \%$ (13) of respondents have established an external steering group for LAQM whereas only $27 \%$ (3) have established an equivalent group for carbon management. The opportunity to utilise established LAQM networks for the purpose of carbon management has been recognised by a number of air quality officers and articulated in case study interviews. For example: "To make a difference, there has to be contact with emitters at a local level, and air quality officers are best suited for this role as there would already be contacts and expertise regarding air quality, emissions, etc." (City Council Air Quality Officer).

Air Quality Officers have also developed a great deal of technical expertise through the LAQM process. Many of these skills would also be required for implementing a comprehensive strategy for carbon management such as the production of robust emissions inventories and identification of priority polluters, both necessary for establishing a baseline from which emissions reductions can be measured. Responding Air Quality Officers confirmed this point in the 2008 questionnaire survey by ranking the production of emission inventories as the most transferable aspect of the LAQM process (see Table 1). 
Table 1: $\quad$ Mean ranked score of the most transferable aspects of LAQM for the management of carbon emissions.

\begin{tabular}{|l|l|}
\hline Components of LAQM process & Mean score \\
\hline Emissions Inventories & 4.16 \\
\hline Action Plan & 3.53 \\
\hline Updating and Screening Assessment & 3.00 \\
\hline Detailed Assessment & 2.26 \\
\hline Further Assessment & 2.00 \\
\hline Progress Report & 2.00 \\
\hline
\end{tabular}

(scale: $1-6$, where $1=$ not transferable and $6=$ highly transferable).

The skills developed through a decade of LAQM could be exploited as an efficient and effective use of scarce local authority resources for the purposes of carbon management. Further to this point, some air quality officers expressed concern that not utilising the LAQM regulatory framework, and the existing skills and networks developed through the process, would result in a duplication of effort and funding streams. For example: “...it would be senseless to invent a duplicate regulatory regime to deal with carbon emissions when a regime with complementary skills already exists. It is particularly important if there likely to be an $A Q$ benefit through the management of carbon." (District Authority Air Quality Officer).

AQAPs are the vehicle by which local authorities outline the measures they will take to work towards meeting the AQOs. Local authorities must take care to ensure that the measures they select for inclusion in the AQAP do not impact negatively on other environmental concerns. Due to the strong commonality between the sources of air pollution and carbon emissions at a local level, it would be judicious for local authorities to identify measures that will improve air quality while reducing overall emissions of carbon and, where possible, avoid actions that will result in an increase in carbon emissions. The 2009 questionnaire survey showed that $63 \%$ (10) of the respondents think that AQAPs should consider their impact on carbon emissions. This recognition of the potential impact of air pollution control measures on carbon emissions was further highlighted by one Air Quality Officer, who stated that: "Carbon emissions should be considered within the AQAP as it is important that measures that reduce $\mathrm{NO}_{2}$ and $\mathrm{PM}_{10}$ [the main pollutants of concern in most AQAPs] also reduce $\mathrm{CO}_{2}$. A measure that reduces these pollutants but increases $\mathrm{CO}_{2}$ should be avoided." (District Authority Air Quality Officer). This positive expression of the importance of considering the wider non-air quality impacts of measures illustrates a shift in attitude in recent years. In the 2008 questionnaire survey of the same group, only $27 \%$ (3) of the respondents considered non-air quality issues in the development of their AQAP. Furthermore, the mean score on a Likert scale ranked question showed that consideration of carbon emissions was 'limited or absent' in the development of measures for AQAPs. However, in the 2009 questionnaire survey, 73\% (11) of respondents stated that they were 
'likely' or 'highly likely' to prioritise actions likely to reduce air pollution and carbon emissions in tandem in future AQAPs.

\subsection{Barriers to integrated management of air pollution and carbon emissions}

Despite the opportunities the LAQM regime presents for aiding local authority carbon management initiatives, there are a number of barriers that exist to the achievement of a comprehensive integration of the two policy areas. As previously mentioned, there remains a lack of dedicated climate change staff that can co-ordinate a local authorities approach to carbon management. This results in action being fragmented within authorities, and an inconsistency in approach between authorities. While 89\% (8) of respondents to the 2009 questionnaire survey reported having an officer with responsibility for carbon management, this role is predominantly an auxiliary function of their primary profession (e.g. forward planning, facilities management, environmental protection or waste management). Case study participants expressed frustration that their duty to fulfil their primary role leaves insufficient time and resources to coordinate and effectively implement carbon abatement measures. For example, one officer stated:" I'm dealing with climate change but I am still a planner. We haven't got a dedicated officer. I have to do it along side my planning job so one must question the commitment of this authority." (District Authority Officer with carbon management responsibilities).

There are various possible explanations for the lack of commitment displayed by local authorities in the South West Region of England. During the 2008 questionnaire survey, respondents that had not yet produced a strategy for tackling climate change were asked to rank a compendium of reasons for inaction. The highest scoring reason given was 'not a statutory requirement' followed by 'other issues having higher priority' and 'lack of time'. This suggests that the lack of a strong statutory framework is a primary barrier to local authority action on climate change and carbon management. The need for a statutory requirement to drive action on carbon mitigation was echoed in the case study interviews. "You can't get away from the need for statutory targets and regulation from central government. Even in a single-tiered government. They [local authorities] will only do what they are told to do." (City Council Officer with carbon management responsibilities).

A statutory requirement could impel management of carbon emissions at a local level and necessitate the allocation of time and resources. Integration of elements of carbon emission management into the LAQM framework could prove an efficient use of these resources: "A statutory requirement is needed to force local governments to release funding to enable us to do it properly, rather than just trying to do it in our spare time within our existing operational budgets. However, utilising existing skills and networks of the Air Quality Officers could reduce the overall cost of required action." (District Authority Officer with carbon management responsibilities). This principal explanation, in addition to others deduced by this research, is applicable to other local government organisation across the UK. 
Table 2: $\quad$ Number of measures identified in AQAPs that are likely to result in synergistic or trade-off outcomes.

\begin{tabular}{|l|c|c|c|}
\hline & Synergies & Trade-offs & Total \\
\hline Number & 141 & 69 & 210 \\
\hline
\end{tabular}

Table 3: $\quad$ Number of direct/indirect measure in AQAPs that are likely to result in synergistic or trade-off outcomes.

\begin{tabular}{|l|c|c|}
\hline & Synergies & Trade-offs \\
\hline Direct Measures & 47 & 64 \\
\hline Indirect Measures & 94 & 5 \\
\hline
\end{tabular}

\subsection{Challenges for integrated management of air pollution and carbon emissions}

One element of the secondary data analysis was to examine the measures identified by AQAPs to assess their likely impact on air pollution and carbon emissions. Part of this process involved the construction of a matrix to examine the likelihood that the specified measures would result in a synergy or trade-off for air quality and carbon emissions. Table 2 shows the aggregate number of measures in South West England that are likely to result in a synergy or trade-off outcome.

The above table shows that $67 \%$ (141) of the 210 measures being implemented specifically for air quality in the AQAPs are likely to simultaneously benefit air quality and reduce carbon emissions. The remaining $33 \%$ may represent currently missed opportunities. The professed absence of consideration of carbon emissions in the development of AQAPs suggests that most actions taken to improve air quality will be co-beneficial, resulting in complementary reductions in carbon emissions. It would seem likely therefore that, if local authorities were to consider carbon emissions during the development of AQAPs, the percentage of co-beneficial actions could be substantially increased. However, care should be taken to ensure that the pursuit of synergistic measures for air and carbon emissions does not incapacitate the ability of AQAPs to deliver tangible improvements in local air quality. To investigate this issue further, the identified measures were collated into direct measures (measures which local authorities have direct powers implement) and indirect measures (measures that local authorities cannot directly implement but seek to influence indirectly). The results are summarised in Table 3.

It is apparent that, while only $42 \%$ (47) of direct measures implemented in AQAPs will result in associated reductions in carbon emissions, 95\% (94) of indirect measures result in synergy between the two areas. This would suggest that local authorities should pursue indirect actions in their AQAPs if they wish to deliver simultaneous reductions in carbon emissions. However, in many cases, the indirect measure will be poorly suited to improve the hotspots identified by the LAQM process. Conversely the more physical management (rerouting 
traffic, bypass, low emission zone etc.) that characterises the direct action may be sufficient to deliver such improvements. This observation was mirrored by one case study authority when discussing the implications of direct and indirect measures: "They [indirect measures] are what I would call 'softer' measures, less dramatic in terms of $A Q$ impact. If the introduction of carbon emissions into AQAPs eliminates the option of direct measures I think we may struggle to bring significant improvements in air quality in the hotspots." (District Authority Air Quality Officers). Another possible explanation is that indirect measures require negotiation with partner organisations with different priorities and perspectives, amplifying the value of co-creation of more far-sighted and inclusive outcomes by networks of stakeholders.

This also highlights one of the core differences between carbon management and air quality management in the UK. LAQM is a health-based framework focusing on receptor exposure. Thus, AQOs are only exceeded in areas were receptors are likely to be exposed to the offending pollutant(s). This provides scope for the sources of emissions to be isolated and separated from the receptor without the need to reduce overall emissions. Conversely, carbon mitigation is concerned with reduction in total load of emissions. It follows that, while it the LAQM process is focused on managing relatively small 'pockets' of poor air quality, it will be difficult to effectively integrate the management carbon emissions within the existing framework and ancillary benefits for carbon reductions will be limited.

\section{Conclusions}

Local authorities in South West England appear to be making progress in the area of carbon management. This has predominantly been driven by proactive local authority engagement in voluntary initiatives. The National Performance Reporting Framework is likely to further stimulate growth in the area. However, in the absence of statutory targets for reducing carbon emissions, local governments seem unwilling to provide additional funding and resources to address the issue. In order to utilise scarce resources in the most efficient manner, local authorities should draw upon the existing complementary skills developed by Air Quality Officers through the LAQM regime.

Due to the common sources of emission of both air quality pollutants and greenhouse gases, management measures are likely to impact upon one another. The Air Quality Strategy recognises the importance of these links and is urging local governments to consider their impact on carbon emissions and prioritise synergistic actions where possible. The majority of air quality officers participating in this research project believe that AQAPs should consider their impact on carbon emissions. However, while the LAQM process continues to focus on a 'hotspot' approach, local authorities may find it difficult to remediate areas of poor air quality without impacting negatively on carbon emissions. Acknowledgment: the authors gratefully acknowledge the support of Great Western Research, the Environment Agency and AAR Environmental Ltd which enabled this research to be undertaken. 


\section{References}

[1] HM Government, Climate Change Act 2008. The Stationary Office, 2008.

[2] United Nations, United Nations Framework Convention on Climate Change. http://unfccc.int/2860.php

[3] Kyoto Protocol. http://unfccc.int/

[4] European Commission, 2007. EU Action Against Climate Change. EU Emissions Trading: An open system promoting global innovation. European Union Publications Office, 2007.

[5] Defra, Climate Change: the UK Programme. The Stationary Office, 2006.

[6] Energy Savings Trust, Nottingham Declaration on Climate Change. http://www.energysavingtrust.org.uk/housingbuildings/localauthorities/Nott inghamDeclaration.

[7] Carbon Trust, Carbon Trust's Local Authority Carbon Management Programme. Available from: http://www.carbontrust.co.uk, 2008.

[8] HM Government and LGA, An introduction to the Local Performance Framework - delivering better outcomes for local people. Wetherby: Communities and Local Government Publications. 2007

[9] Hayes, E.T., Leksmono, N.S., Chatterton, T.J., Symons, J.K., Baldwin, S.T., and Longhurst, J.W.S., Co-management of carbon dioxide and local air quality pollutants: identifying the 'win-win' actions. Proc. Of the $14^{\text {th }}$ Int. Conf. IUAPPA World Congress: Brisbane, 2007.

[10] Vuuren, D., Cofala, J., Eerens, H., Oostenrijk, R., Heyes, C., Klimont, K., den Elzen, M. \& Amann, M., Exploring the ancillary benefits of the Kyoto Protocol for air pollution in Europe. Energy Policy 34, pp. 444-460, 2006.

[11] Stern, N., The Economics of Climate Change: The Stern Review, Cambridge University Press: Cambridge, UK, 2007.

[12] European Environment Agency, Air quality and ancillary benefits of climate change policies. Luxembourg: Office for Official Publications of the European Communities, 2006.

[13] Air Quality Expert Group, Air quality and climate change: a UK perspective. Defra: London, 2006.

[14] HM Government, Environment Act 1995. The Stationery Office, 1995.

[15] Longhurst, J.W.S., Beattie, C.I., Chatterton, T.J., Hayes, E.T., Leksmono, N.S., \& Woodfield, N.K., Local air quality management as a risk management process: assessing, managing and remediating the risk of exceeding an air quality objective in Great Britain. Environment International 32, pp. 934-947, 2006.

[16] Beattie, C.I. \& Longhurst, J.W.S., Joint Working within Local Government: air quality as a case study. Local Environment 5, pp. 401-414, 2000.

[17] Defra, The Air Quality Strategy for England, Scotland, Wales and Northern Ireland. The Stationery Office, 2007. 